Research Article

Human and Medical Genetics

\title{
Newborn screening for lysosomal disorders in Brazil: A pilot study using customized fluorimetric assays
}

Fernanda Bender ${ }^{1,2}$, Maira G. Burin ${ }^{1}$, Kristiane M. Tirelli ${ }^{1}$, Fernanda Medeiros ${ }^{1,2}$, Fernanda Hendges de Bitencourt $^{1,3}$ iD , Gabriel Civallero ${ }^{1}$, Francyne Kubaski ${ }^{1,3,4}$ iD, Heydy Bravo ${ }^{1}$, Antoine Daher ${ }^{5}$, Vanessa Carnier ${ }^{5}$, José F. S. Franco ${ }^{6}$ and Roberto Giugliani ${ }^{1,2,3,4}$

${ }^{1}$ Hospital de Clínicas de Porto Alegre, Medical Genetics Service, Porto Alegre, RS, Brazil.

${ }^{2}$ Universidade Federal do Rio Grande do Sul (UFRGS), Programa de Pós-Graduação em Médicas: Ciências Médicas, Porto Alegre, RS, Brazil.

${ }^{3}$ Instituto Nacional de Genética Médica Populacional (INAGEMP), Porto Alegre, RS, Brazil.

${ }^{4}$ Universidade Federal do Rio Grande do Sul (UFRGS), Departamento de Genética, Porto Alegre, RS,

Brazil.

${ }^{5}$ Casa Hunter, São Paulo, SP, Brazil.

${ }^{6}$ Pontifícia Universidade Católica de Campinas, Hospital e Maternidade Celso Pierro, Campinas, SP, Brazil.

\begin{abstract}
Lysosomal storage disorders (LSDs) are a group of genetic disorders characterized by deficiency of specific lysosomal enzymes. In general, patients are clinically normal at birth, and progressively develop severe signs and symptoms. Diagnosis is usually made several years after onset of manifestations, preventing patients to have the benefits of the early treatment. Newborn screening programs are being considered for LSDs to allow early diagnosis and treatment. The present study evaluated the feasibility of a customized screening approach based on modified fluorometric assays with reduced amounts of reagents, substrates and samples for: mucopolysaccharidosis (MPS) type I (MPS I), MPS VI, Fabry, Gaucher, and Pompe diseases. We also evaluated the advantages of including blood chitotriosidase and urinary glycosaminoglycans in the protocol. By the measurement of the specific diseaseassociated enzymes (plus blood chitotriosidase and urinary glycosaminoglycans) we analyzed 834 de-identified DBS of unselected newborns. No positive case was detected, and the false-positive rates were low. Taking into consideration the limitations of this methodology, we believe that, after defining proper cutoffs, it could be a viable alternative to provide NBS for LSDs by laboratories that may not be able to afford the commercial methods available.
\end{abstract}

Keywords: Inborn errors of metabolism, newborn screening, enzymes.

Received: November 15, 2018; Accepted: May 25, 2019.

\section{Introduction}

Lysosomal storage disorders (LSDs) are a group of inborn errors of metabolism (IEM) that result from the deficiency of specific hydrolases, protein activators or transport proteins, leading to an accumulation of undegraded substrates in lysosomes leading to biochemical changes and even cell death (Tager et al., 1984).

LSDs include over 50 genetic disorders with specific characteristics (Bellettato and Scarpa, 2010). Although, they are considered individually rare, when combined they are estimated to occur in 1:7,700 live births (Meikle et al.,

Send correspondence to Fernanda Bender. Medical Genetics Service, Hospital de Clínicas de Porto Alegre, Medical Genetics Service, Rua Ramiro Barcelos 2350, 90035-903 Porto Alegre, RS, Brazil. E-mail: bender.fernanda@gmail.com.
1999). The incidence of LSDs in Brazil is still not clear. A study reported that LSD corresponded to $60 \%$ of the IEM diagnosed from 1982 to 2015 at a reference laboratory in Brazil (Giugliani et al., 2017).

Newborn screening (NBS) allows the early diagnosis of several congenital disorders that are mainly asymptomatic at the newborn period. The diagnosis allows early treatment in order to at least slow down the disease progression (http://portalms.saude.gov.br/acoes-e-programas/programanacional-da-triagem-neonatal). Ideally, the tests included in an NBS program should be based in a reliable methodology and should have the possibility of multiplexing.

In Brazil, there are few records of NBS programs involving LSDs. In Porto Alegre in southern Brazil, the private laboratory CTN screened 10,527 babies for Fabry, Gaucher, Pompe, and MPS I. All initially positive cases 
were further studied until a conclusion was made, and no diagnosis was confirmed (Camargo Neto et al., 2018). In Monte Santo, Bahia state, where there is a high incidence of MPS VI (approximately 1:5,000), a common mutation (p.His178Leu) was found in homozygosis in 13 patients and a high carrier frequency $(40 \%)$ was observed (CostaMotta et al., 2011), confirming that a founder effect and endogamy play a major role in this case. A newborn screening pilot program for MPS VI (based on the detection of the common mutation) was introduced in Monte Santo and already tested over 5,000 babies (Bender, 2011).

Here, our aim was to test customized fluorometric methods for assaying five lysosomal enzymes in screens for MPS I, MPS VI, Fabry, Gaucher, and Pompe diseases, plus assays of biomarkers, such as blood chitotriosidase and urinary glycosaminoglycans. The feasibility of these methods was evaluated, in order to consider them as a potential alternative to commercially available methods.

\section{Materials and Methods}

\section{Materials}

The following reagents 4-methylumbelliferyl acetate, 4-methyllumbelliferyl- $\alpha-\mathrm{D}$ galactopyranoside, N-acetilD-galactosamine, 4-methyllumbelliferyl- $\beta$-D-glucopyranoside, taurodeoxycholate hydrate, acarbose, 4-methyllumbelliferyl- $\alpha$-D-glucopyranoside, 4-methylumbelliferyl $\beta$-D-N,N',N' 'triacetylchitotrioside, ethylenediamine dihydrochloride, formic acid, chondroitin sulfate sodium salt from shark cartilage, 1,9-dimethyl-methylene blue zinc chloride double salt, sodium hydroxide $(\mathrm{NaOH})$ were purchased from Sigma-Aldrich (St. Louis, MO, USA). 4-methyllumbelliferyl sulfate potassium and 4-methyllumbelliferyl $\alpha$-L-iduronide were purchased from Glycosynth (Warrington, UK). Sodium acetate, sodium citrate, sodium phosphate, and aminoacetic acid (glycine) were purchased from Synth (São Paulo, Brazil).

\section{Subjects}

DBS samples of 834 newborns were collected at the Hospital da Pontifícia Universidade Católica (PUC) Campinas and Hospital Maternidade Celso Pierr, both in Campinas, SP, Brazil, after informed consent was obtained. Urine samples of 722 newborns were obtained from the same hospital, also after informed consent was obtained. Reference values for each of the analyzed enzymes for newborns were established using 131 de-identified DBS samples from healthy newborns, supplied by a commercial laboratory. As no positive samples of newborns were available, samples of patients diagnosed later in life (MPS I: 22, MPS VI: 24, Fabry: 12, Gaucher: 29, Pompe: 14) were used to establish the affected reference levels. All samples were shipped to the Medical Genetics Service (MGS) of Hospital de Clínicas de Porto Alegre (HCPA) and stored at $-20^{\circ} \mathrm{C}$ until the assays were conducted. This study was approved by the Institutional Review Board (IRB) from HCPA and from the Hospital da PUC-Campinas and Hospital Maternidade Celso Pierro (CAAE number: 2.824.531).

\section{Sample preparation}

Enzyme assays were performed in a PerkinElmer incubator at $40 \mathrm{rpm}$. Fluorescence was measured in the supernatant by spectrofluorometry (Spectramax M2, Molecular Devices, San José, CA, USA) with $365 \mathrm{~nm}$ for excitation and $450 \mathrm{~nm}$ of emission. The results for 4-metilumbeliferone and enzyme activity were expressed as $\mathrm{nmol} / \mathrm{h} / \mathrm{mL}$. All assays were done in duplicates.

\section{Alpha-L-iduronidase (IDUA) assay}

One disk $(1.5 \mathrm{~mm})$ was cut from DBS samples and placed into a 96 well plate with $10 \mu \mathrm{L}$ of deionized water (MilliQ, Millipore, Burlingto, MA, USA), $10 \mu \mathrm{L}$ of $50 \mathrm{mM}$ formate buffer ( $\mathrm{pH} 2.8$ ) and $7 \mu \mathrm{L}$ of $2 \mathrm{mM}$ 4-methyllumbelliferyl- $\alpha$-L-iduronide substrate diluted in MilliQ water. In the blank wells, $240 \mu \mathrm{L}$ of $0.5 \mathrm{M}$ glycine- $\mathrm{NaOH}$ buffer ( $\mathrm{pH}$ 10.3) were added. After mixing, the microplates were sealed and incubated per $20 \mathrm{~h}$ at $37^{\circ} \mathrm{C}$ on a shaker (400 rpm). After incubation, the reactions were stopped by addition of $240 \mu \mathrm{L}$ of $0.5 \mathrm{M}$ glycine- $\mathrm{NaOH}$ buffer ( $\mathrm{pH}$ 10.3). Samples were centrifuged at 2,500 rpm for $10 \mathrm{~min}$ at room temperature.

\section{Arylsulfatase B (ARSB) assay}

One disk $(1.5 \mathrm{~mm})$ was cut from DBS samples and placed into a 96 well plate with $11.5 \mu \mathrm{L}$ of MilliQ water, 7.5 $\mu \mathrm{L}$ of $15 \mathrm{mM}$ lead acetate (pH 5) in $0.05 \mathrm{M}$ of sodium acetate buffer (pH 5) and $18.75 \mu \mathrm{L}$ of $10 \mathrm{mM}$ 4-methylumbelliferyl-sulfate diluted in $0.05 \mathrm{M}$ sodium acetate $(\mathrm{pH}$ 5). In the blank wells, $112.5 \mu \mathrm{L}$ of $0.085 \mathrm{M}$ glycine- $\mathrm{NaOH}$ buffer ( $\mathrm{pH} 10.5$ ) were added. After mixing, the microplates were sealed and incubated per $20 \mathrm{~h}$ at $37^{\circ} \mathrm{C}$ on a shaker (400 rpm). After incubation, the reactions were stopped by addition of $112.5 \mu \mathrm{L}$ of $0.085 \mathrm{M}$ glycine- $\mathrm{NaOH}$ buffer $(\mathrm{pH}$ $10.5)$. Samples were centrifuged at 3,000 rpm for $10 \mathrm{~min}$ at $4{ }^{\circ} \mathrm{C}$.

\section{Alpha-galactosidase A (GLA) assay}

One disk $(1.5 \mathrm{~mm})$ was cut from DBS samples and placed into a 96 well plate with $20 \mu \mathrm{L}$ of $0.25 \mathrm{M} \mathrm{N}$-acetylD-galactosamine inhibitor, $50 \mu \mathrm{L}$ of 4-methylumbellife ryl- $\alpha$-D-galactoside substrate diluted in $0.15 \mathrm{M}$ citratephosphate buffer (pH 4.4). In the blank wells, $230 \mu \mathrm{L}$ of 0.1 $\mathrm{M}$ ethylenediamine buffer ( $\mathrm{pH}$ 11.4) were added. After mixing, the microplates were sealed and incubated per $20 \mathrm{~h}$ at $37^{\circ} \mathrm{C}$ on a shaker $(400 \mathrm{rpm})$. After incubation, the reactions were stopped by addition of $230 \mu \mathrm{L}$ of $0.1 \mathrm{M}$ ethy- 
lenediamine buffer ( $\mathrm{pH}$ 11.4). Samples were centrifuged at $2,000 \mathrm{rpm}$ for $5 \mathrm{~min}$ at room temperature.

\section{Beta-glucocerebrosidase (ABG) assay}

One disk $(1.5 \mathrm{~mm})$ was cut from DBS samples and placed into a 96 well plate with $12.5 \mu \mathrm{L}$ of $0.54 \mathrm{M}$ citrate-phosphate buffer (pH 5.5), $25 \mu \mathrm{L}$ of $10 \mathrm{mM}$ 4-methylumbelliferyl- $\beta$-D-glucoside substrate and $50 \mathrm{mM}$ sodium taurodeoxycholate diluted in MilliQ water. In the blank wells, $250 \mu \mathrm{L}$ of $0.5 \mathrm{M}$ glycine- $\mathrm{NaOH}$ buffer ( $\mathrm{pH} 10.3$ ) were added. After mixing, the microplates were sealed and incubated per $5 \mathrm{~h}$ at $37^{\circ} \mathrm{C}$ on a shaker $(400 \mathrm{rpm})$. After incubation, the reactions were stopped by addition of $250 \mu \mathrm{L}$ of $0.5 \mathrm{M}$ glycine- $\mathrm{NaOH}$ buffer (pH 10.3). Samples were centrifuged at $3,000 \mathrm{rpm}$ for $10 \mathrm{~min}$ at room temperature.

\section{Acid alpha-glucosidase (GAA) assay}

One disk $(1.5 \mathrm{~mm})$ was cut from DBS samples and placed into a 96 well plate with $10 \mu \mathrm{L}$ of MilliQ water, 20 $\mu \mathrm{L}$ of $10 \mathrm{mM}$ 4-methylumbelliferyl- $\alpha$-D-glucoside substrate diluted in $0.2 \mathrm{M}$ citrate-phosphate buffer ( $\mathrm{pH} 4)$ and 8 $\mathrm{mM}$ acarbose diluted in MilliQ water. In the blank wells, $240 \mu \mathrm{L}$ of $0.5 \mathrm{M}$ glycine- $\mathrm{NaOH}$ buffer ( $\mathrm{pH}$ 10.3) were added. After mixing, the microplates were sealed and incubated per $20 \mathrm{~h}$ at $37^{\circ} \mathrm{C}$ with shaker ( $\left.400 \mathrm{rpm}\right)$. After incubation, the reactions were stopped by addition of $240 \mu \mathrm{L}$ of $0.5 \mathrm{M}$ glycine-NaOH buffer (pH 10.3). Samples were centrifuged at 2,000 rpm for $5 \mathrm{~min}$ at room temperature.

\section{Chitotriosidase assay}

One disk $(1.5 \mathrm{~mm})$ was cut from DBS samples and placed into a 96 well plate with $10 \mu \mathrm{L}$ of $0.25 \mathrm{M}$ sodium acetate ( $\mathrm{pH} 5.5), 10 \mu \mathrm{L}$ of $0.19 \mathrm{nM}$ 4-methylumbelliferyl$\beta$-D-N-N'-N"'-triaceltylchitotrioside substrate diluted in MilliQ water. In the blank wells, $250 \mu \mathrm{L}$ of $0.1 \mathrm{M}$ ethylenediamine buffer $(\mathrm{pH}$ 11.3). After mixing, the microplates were sealed and incubated per $30 \mathrm{~min}$ at $37^{\circ} \mathrm{C}$ on a shaker (400 rpm). After incubation, the reaction was stopped by addition of $250 \mu \mathrm{L}$ of $0.1 \mathrm{M}$ ethylenediamine buffer ( $\mathrm{pH}$ 11.3). Samples were centrifuged at 3,000 rpm per $10 \mathrm{~min}$ at room temperature.

\section{Glycosaminoglycans assay}

Urine samples were centrifuged at 2,000 rpm for 10 min. Fifty microliters of sample were mixed with $1.1 \mathrm{~mL}$ of buffer ( $55 \mathrm{mM}$ formic acid buffer, $\mathrm{pH} 3.3$ ) with $31 \mu \mathrm{M}$ of dimethylmethylene-blue and $2 \mathrm{M}$ tris(hydroxymethyl)aminomethane. After vortexing, absorbance was immediately measured in a spectrophotometer at $520 \mathrm{~nm}$. Chondroitin sulfate was used for a calibration curve at the following concentrations: $50 \mathrm{mg} / \mathrm{L}, 25 \mathrm{mg} / \mathrm{L}, 12.5 \mathrm{mg} / \mathrm{L}$ and $5 \mathrm{mg} / \mathrm{L}$. Urinary GAGs were normalized by creatinine, and concentrations were expressed as $\mu \mathrm{g} / \mathrm{mg}$ creatinine.

\section{Statistical analysis}

Sensitivity, specificity, false positives and false negatives were calculated using R software (R Core Team, 2014). Potential cutoff values for the five enzymes were defined using normal newborn percentile obtained from 131 healthy newborns and enzyme level from older patients provided by our laboratory. Enzyme activities for IDUA, ARSB, GLA and GBA were expressed as $\mathrm{nmol} / 20 \mathrm{~h} / \mathrm{mL}$; en zyme activity of $\mathrm{ABG}$ was expressed as $\mathrm{nmol} / 5 \mathrm{~h} / \mathrm{mL}$; glycosaminoglycan concentration was expressed as $\mu \mathrm{g} / \mathrm{mg} /$ creatinine; and chitotriosidase activity was expressed as $\mathrm{nmol} / \mathrm{h} / \mathrm{mL}$.

\section{Results}

The major adaptations in the current methods for these enzyme assays were: reduction of the original reaction volume (substrate/reagents) and reduction of the DBS punch from $3 \mathrm{~mm}$ to $1.5 \mathrm{~mm}$ (Chamoles et al., 2001; Civallero et al., 2006). This led to a cost reduction compared to the original method described by Chamoles et al. (2001).

\section{Sensitivity and specificity}

Sensitivity, specificity, positive and negative predictive values for all enzymes are described in Table 1.

\section{Determination of normal and affected ranges}

In order to define the normal range for each enzyme, DBS from 131 healthy de-identified newborns were analyzed and reference values are described in Table 2. To establish potential disease cutoff values, samples of known patients were analyzed for MPS I (22), MPS VI (24), Fabry (12), Gaucher (29), and Pompe (14) (Table 2).

\section{Determination of normal and affected ranges}

\section{Cutoff values}

In this study, 834 DBS samples of newborns were analyzed. The distributions of the five enzymes are shown in Figure 1. Initial cutoffs were set as values below the reference values established in healthy de-identified newborns (IDUA $<0.8 \mathrm{nmol} / 20 \mathrm{~h} / \mathrm{mL}$; ARSB $<3 \mathrm{nmol} / 20 \mathrm{~h} / \mathrm{mL}$; GLA

Table 1 - Sensitivity, specificity, positive predictive values, and negative predictive values for the five analyzed enzymes.

\begin{tabular}{lcccc}
\hline Enzyme & Sensitivity & Specificity & PPV & NPV \\
\hline$I D U A$ & $100 \%$ & $94 \%$ & $32 \%$ & $100 \%$ \\
$A R S B$ & $100 \%$ & $99.7 \%$ & $89 \%$ & $100 \%$ \\
$G L A$ & $100 \%$ & $99.9 \%$ & $93 \%$ & $100 \%$ \\
$A B G$ & $100 \%$ & $98 \%$ & $67 \%$ & $100 \%$ \\
$G A A$ & $100 \%$ & $97 \%$ & $36 \%$ & $100 \%$ \\
\hline
\end{tabular}

IDUA: alpha-L-iduronidase; ARSB: arylsulfatase B; GLA: alpha-galactosidase A; ABG: beta-glucocerebrosidase; GAA: acid alpha-glucosidase; PPV: positive predictive values; NPV: negative predictive values 
Table 2 - Normal and affected ranges for each enzyme.

\begin{tabular}{lcc}
\hline Enzyme & $\begin{array}{c}\text { Reference range for } \\
\text { healthy newborns }(\mathrm{n}=131)\end{array}$ & Range of affected patients \\
\hline$I D U A$ & $0.8-4^{*}$ & $0-0.5^{*}$ \\
$A R S B$ & $3-16^{*}$ & $0.9-2.4^{*}$ \\
$G L A$ & $4-21^{*}$ & $0.4-1.1^{*}$ \\
$A B G$ & $2-10^{* *}$ & $0.1-1.6^{* *}$ \\
$G A A$ & $12-63^{*}$ & $0-5.5^{*}$ \\
Chitotriosidase & $0-53 \#$ & $166-677 \#$ \\
\hline
\end{tabular}

IDUA: alpha-L-iduronidase; ARSB: arylsulfatase B; GLA: alpha-galactosidase A; ABG: beta-glucocerebrosidase; GAA: acid alpha-glucosidase; * nmol $/ 20 \mathrm{~h} / \mathrm{mL} ;{ }^{*} * \mathrm{nmol} / 5 \mathrm{~h} / \mathrm{mL} ; \# \mathrm{nmol} / \mathrm{h} / \mathrm{ml}$.
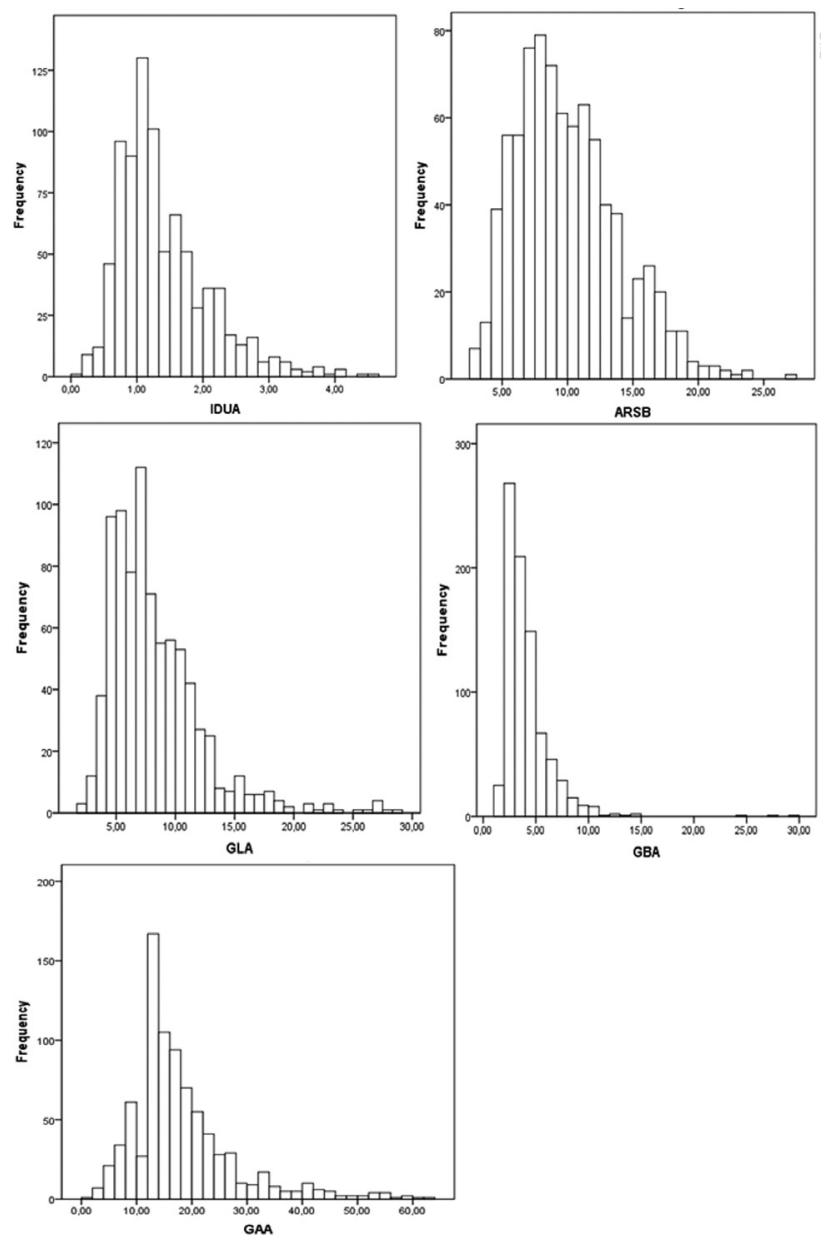

Figure 1 - Distribution of the five enzymes analyzed in this study by fluorimetry. IDUA: alpha-L-iduronidase; ARSB: arylsulfatase B; GLA: alpha-galactosidase A; ABG: beta-glucocerebrosidase; GAA: acid alpha-glucosidase.

$<4 \mathrm{nmol} / 20 \mathrm{~h} / \mathrm{mL} ; \mathrm{ABG}<12 \mathrm{nmol} / 5 \mathrm{~h} / \mathrm{mL}$ and GAA $<2$ $\mathrm{nmol} / 20 \mathrm{~h} / \mathrm{mL}$ ) (Table 2). Using these reference values, the false positive rates were: $10.5 \%$ for IDUA $(n=88), 0.8 \%$ for $\operatorname{ARSB}(n=3), 3.7 \%$ for GLA $(n=31), 3 \%$ for ABG $(n=25)$, and $18 \%$ for GAA $(n=150)$.
In order to decrease the false positive rates, we decided to use the highest enzyme level of known patients. With this we aimed at avoiding any false negative, once all of these were lower than the lowest value of the reference range for healthy newborns (Table 2). Thus, false positive rates decreased to: $5.5 \%$ for IDUA $(n=46), 0.8 \%$ for ARSB, $0 \%$ for GLA, $1.7 \%$ for $A B G(n=14)$, and $3 \%$ for GAA $(n=25)$.

For MPS I, MPS VI, and Gaucher disease we also used a second-tier test in order to further decrease the false positive rates. For MPS I and VI we used urinary GAGs as a biomarker, and for Gaucher disease chitotriosidase in DBS. For MPS I, the original false positive rates were 5.5\% $(n=46)$ using reference range, and of these $76 \%(n=35)$ had urine samples for GAG measurement all within normal levels (reference range up to 6 months: $133-460 \mu \mathrm{g} / \mathrm{mg} / \mathrm{crea}-$ tinine). Thus, false positive rates decreased even further to $1.3 \%$. For the three MPS VI cases with low ARSB levels, two had urine available for GAG measurement, with normal GAG levels resulting in $0.1 \%$ false positives. For Gaucher disease, we used the measurement of chitotriosidase to reduce the false positive rates. Of the $1.7 \%$ $(n=14)$, only one had elevated levels of chitotriosidase $(62$, reference range: $0-53 \mathrm{nmol} / \mathrm{h} / \mathrm{mL}$ ), reducing the false positive rate to $0.1 \%$.

All samples with abnormal enzyme levels will be further investigated by the measurement of enzyme activity in leukocytes, as well as gene sequencing to exclude any abnormality.

\section{Discussion}

Newborn screening for lysosomal diseases has been performed regularly since 2006 for Krabbe disease, in the state of New York, USA (Orsini et al., 2016), and is being included in the newborn screening panels by several states in the USA (Hopkins et al., 2015; Burton et al., 2017), being already an official recommendation for MPS I and Pompe (Minter Baerg et al., 2018). It is also a regular practice in Taiwan (Chuang et al., 2018) and in some regions of Italy (Burlina et al., 2018). All the efforts to include LSDs to NBS are due to the lack of clinical signs at birth, the progressive characteristic of these disorder, and availability of treatment that seems to be more effective when started early (McGill et al., 2010; Giugliani et al., 2010).

Newborn screening for lysosomal storage disorders can be done by fluorometry or tandem mass spectrometry (MS/MS). The superior analytical range of MS/MS compared to fluorimetric assays has already been described by several groups (Gelb et al., 2015; Kumar et al., 2015; Schielen et al., 2017). However, a digital microfluid method has been used by several centers with optimized cutoffs to decrease false positive rates (Hopkins et al., 2015).

This study has several limitations, such as the lack of newborn samples of known patients to determine and vali- 
date the cutoffs, the inability to multiplex the five substrates due to the same excitation/emission wavelength for all enzymes, and the fact that all the reagents were made "inhouse", without the manufacturing standardization of commercially available kits.

For MPS I, MPS VI and Gaucher disease we were able to reduce the false positive rates using a second-tier approach throughout biomarker measurement (glycosaminoglycans for MPS and chitotriosidase for Gaucher). Nonetheless, for Pompe disease we had false positives rates that were higher compared to the other disorders. This could have been caused by the fact that the acid alphaglucosidase (GAA) substrate preparation requires a much higher temperature $\left(50-60{ }^{\circ} \mathrm{C}\right)$, which could potentially affect the enzyme reaction. Another technique that produces lower false positive rates has been described for detection of Pompe disease (communication from LEIM-HCPA). However, more steps in the sample preparation are required, as well as higher amounts of sample, which could potentially make it unsuitable for mass screening.

We conclude that these optimized methods are efficient and feasible for detection of five LSDs in NBS. These new methods allowed a reduction of $50 \%$ of the original cost (from US\$ 60.00 to US\$ 30.00 per sample, for all the assays) which could potentially enable their adoption for the screening of LSDs in lower-income countries, or in centers that do not have access to tandem mass spectrometry.

\section{Acknowledgments}

We would like to thank all patients and families. This work was supported by INAGEMP. FB and FK conducted this work during scholarships financed by CAPES - Brazil, Finance code 001. RG is a recipient of $\mathrm{CNPq}$ - Brazil research scholarship.

\section{Conflict of interest}

The authors declare no conflict of interest.

\section{Author Contributions}

FB is the primary author of this article. She has contributed to the concept, planning, data analysis, and reporting of the work described. MGB has contributed to the data analysis. KMT has contributed to the biochemical analysis. FM has contributed to the biochemical investigation. FHB has contributed to biochemical analysis. GC has contributed to the biochemical investigations and data analysis. FK has contributed to the concept, planning, data analysis, and reporting of the work described HB has contributed to the biochemical investigation. AD has contributed with sample collection and shipment. VC has contributed with sample collection and shipment. JFSF has contributed to the concept, planning, data analysis, and reporting of the work described. RG has contributed to the concept, planning, data analysis, and reporting of the work described.

\section{References}

Bellettato CM and Scarpa M (2010) Pathophysiology of neuropathic lysosomal storage disorders. J Inherit Metab Dis 33:347-362.

Bender F (2011) Triagem neonatal para mucopolissacaridose tipo VI (Síndrome de Maroteux-Lamy) em uma região com alta incidência da doença. M. Sc.Thesis, Universidade Federal do Rio Grande do Sul, Porto Alegre, $88 \mathrm{p}$.

Burlina AB, Polo G, Salviati L, Duro G, Zizzo C, Dardis A, Bembi B, Cazzorla C, Rubert L, Zordan R et al. (2018) Newborn screening for lysosomal storage disorders by tandem mass spectrometry in North East Italy. J Inherit Metab Dis 41:209-219.

Burton BK, Charrow J, Hoganson GE, Waggoner D, Tinkle B, Braddock SR, Schneider M, Grange DK, Nash C, Shyrock H et al. (2017) Newborn screening for lysosomal storage disorders in Illinois: The initial 15-month experience. J Pediatr 190:130-135.

Camargo Neto E, Schulte J, Pereira J, Bravo H, Sampaio-Filho C and Giugliani R (2018) Neonatal screening for four lysosomal storage diseases with a digital microfluidics platform: initial results in Brazil. Genet Mol Biol 41:414-416.

Chamoles NA, Blanco MB, Gaggioli D and Casentini C (2001) Hurler-like phenotype: Enzymatic diagnosis in dried blood spots on filter paper. Clin Chem 47:2098-102.

Chuang CK, Lin HY, Wang TJ, Huang YH, Chan MJ, Liao HC, Lo YT, Wang LY, Tu RY, Fang YY et al. (2018) Status of newborn screening and follow up investigations for mucopolysaccharidoses I and II in Taiwan. Orphanet J Rare Dis 13:84.

Civallero G, Michelin K, de Mari J, Viapiana M, Burin M, Coelho JC and Giugliani R (2006) Twelve different enzyme assays on dried-blood filter paper samples for detection of patients with selected inherited lysosomal storage diseases. Clin Chim Acta 372:98-102.

Costa-Motta FM, Acosta AX, Abé-Sandes K, Bender F, Schwartz IVD, Giugliani R and Leistner-Segal S (2011) Genetic studies in a cluster of mucopolysaccharidosis type VI patients in Northeast Brazil. Mol Genet Metab 104:603-607.

Gelb MH, Scott CR and Turecek F (2015) Newborn screening for lysosomal storage diseases. Clin Chem 61:335-346.

Giugliani R, Federhen A, Michelin-Tirelli K, Riegel M and Burin M (2017) Relative frequency and estimated minimal frequency of Lysosomal Storage Diseases in Brazil: Report from a Reference Laboratory. Genet Mol Biol 40:31-39.

Giugliani R, Federhen A, Rojas MVM, Vieira T, Artigalás O, Pinto LL, Azevedo AC, Acosta A, Bonfim C, Lourenço CM et al. (2010) Mucopolysaccharidosis I, II, and VI: brief review and guidelines for treatment. Genet Mol Biol 33:589-604.

Hopkins PV, Campbell C, Klug T, Rogers S, Raburn-Miller S and Jami K (2015) Lysosomal storage disorder screening implementation: Findings from the first six months of full population pilot testing in Missouri. J Pediatr 166:172-177.

Kumar AB, Masi S, Ghomashchi F, Chennamaneni NK, Ito M, Scott CR, Turecek F, Gelb MH and Spacil Z (2015) Tandem mass spectrometry has a larger analytical range than fluorescence assays of lysosomal enzymes: application to newborn screening and diagnosis of mucopolysaccharidoses types II, IVA, and VI. Clin Chem 61:1363-1371.

McGill JJ, Inwood AC, Coman DJ, Lipke ML, Lore D, Swiedler SJ and Hopwood JJ (2010) Enzyme replacement therapy for 
mucopolysaccharidosis VI from 8 weeks of age-a sibling control study. Clin Genet 77:492-8.

Meikle PJ, Hopwood JJ, Clague AE and Carey WF (1999) Prevalence of lysosomal storage disorders. JAMA 281:249-54.

Minter Baerg MM, Stoway SD, Hart J, Mott L, Peck DS, Nett SL, Eckerman JS, Lacey JM, Turgeon CT, Gavrilov D et al. (2018) Precision newborn screening for lysosomal disorders. Genet Med 20:847-854.

Orsini JJ, Kay DM, Saavedra-Matiz CA, Wenger DA, Dufner PK, Erbe RW, Biski C, Martin M, Krein LM, Nichols M et al. (2016) Newborn screening for Krabbe disease in New York State: The first eight years' experience. Genet Med 18:239-48.

Schielen PCJI, Kemper EA and Gelb MH (2017) Newborn screening for lysosomal storage diseases: a concise review of the literature on screening methods, therapeutic possibilities and regional programs. Int J Neonatal Screen 3:6.
Tager JM, Jonsson LV, Aerts JM, Elferink RP, Schram AW, Erickson AH and Barranger JA (1984) Metabolic consequences of genetic defects in lysosomes. Biochem Soc Trans 12:902-905.

\section{Internet resources}

Programa Nacional da Triagem Neonatal. http://portalms.saude.gov.br/acoes-e-programas/programa -nacional-da-triagem-neonatal (accessed 2 November 2018 R Core Team (2014) The R Project for Statistical Computing, https://www.r-project.org/.

Associate Editor: Maria Luiza Petzl-Erler

License information: This is an open-access article distributed under the terms of the Creative Commons Attribution License (type CC-BY), which permits unrestricted use, distribution and reproduction in any medium, provided the original article is properly cited. 